\title{
José Pérez Vidal y América
}

\author{
Javier Medina López ${ }^{*}$ \\ Instituto Universitario de Lingüistica "Andrés Bello" \\ Universidad de La Laguna, España
}

\section{INTRODUCCIÓN}

José Pérez Vidal (Santa Cruz de La Palma [Islas Canarias. España], $1907-\uparrow 1990)$ es autor de una de las obras que ha marcado un hito en la historiografía insular canaria: "Aportación de Canarias a la población de América: su influencia en la lengua y en la poesía tradicional", que fue publicada $^{1}$ en 1955. En el año 2005 se cumplieron, pues, los primeros cincuenta años de la edición -pionera en su género, por la enjundia y repercusiones posteriores que tuvo- de un estudio que pone de manifiesto las intensas y fructíferas relaciones de las Islas Canarias con América. Porque el trabajo de Pérez Vidal no solo es importante por ser novedoso en su género, sino porque trazó los caminos de numerosas investigaciones que posteriormente se han hecho después de conocer los datos expuestos por el insigne investigador palmero. En las páginas que siguen trazaré los principales logros de este fundamental artículo, a la vez que pondré de relieve sus aportaciones, cuáles fueron sus fuentes, qué sabía y qué pensaba Pérez Vidal de las relaciones canario-americanas y, en fin, cómo está presente (en

* Para correspondencia, dirigirse a: Javier Medina López (jmedina@ull.es), Facultad de Filología, Universidad de La Laguna, Campus de Guajara s/n, La Laguna, 38071, Tenerife, España.

1 Editado décadas más tarde como libro, junto con un artículo titulado "Poesía tradicional canaria en Méjico" (Las Palmas de Gran Canaria: Cabildo Insular de Gran Canaria, 1991). 
buena medida) América en la producción investigadora del insigne etnógrafo y folclorista palmero ${ }^{2}$. Y en consonancia con el hecho de abrir caminos en este campo, Pérez Vidal (1955: 164) alertó de la carencia de datos y materiales tanto lingüísticos como folclóricos que sentaran las bases de una segura comparación entre la realidad americana y la canaria.

Ya se ha escrito en otra ocasión (Medina López 2008), con motivo del medio siglo de la publicación de este trabajo, que nunca antes se habían trazado de forma tan exhaustiva -y abriendo tantas perspectivas de análisislos vínculos históricos entre las dos realidades atlánticas: la española por parte de Canarias y la americana. A las Islas Canarias se les ha atribuido un papel destacado en la conquista americana, ya que estas supusieron, en realidad, el primer experimento ultramarino que Europa necesitó antes de su expansión definitiva, tal y como ha señalado Morales Padrón (1956: 357). Algunos hablan de la "aportación de los canarios" como entidad ya configurada desde el siglo XVI y, en otros casos, la participación se refiere a una plataforma geográfica a través de la cual se gestionó una compleja red de aspectos especialmente económicos, administrativos, sociales, demográficos, evangélicos, lingüísticos y culturales. Unido a estos hechos, las corrientes migratorias fueron dejando su huella en las nuevas tierras de ultramar. Y una vez que las Islas podían exportar su identidad, el emigrante llevó su manera de pensar, la fuerza y la experiencia de su trabajo, sus creencias religiosas y sus devociones, su manera de organizar el núcleo familiar y su lengua. El continuo trasiego de barcos y gentes en los puertos isleños trajo consigo la adopción de todo aquello que era considerado de interés y no solo en el terreno económico, que lo fue, sino también en el musical, gastronómico, artístico, en la arquitectura doméstica o en las influencias literarias y lingüísticas. En definitiva, la vertiente cultural de las Islas se amplió con la aportación americana en las influencias de vuelta; y proporcionó su sello insular en los territorios descubiertos. Es lo que Alvar (1990: 67) ha descrito como un doble proceso de "adopción" y de "adaptación" que tuvo en las Islas su primer exponente como antesala de América.

En el desarrollo alcanzado por algunas regiones, ciudades y pueblos de América hay que hacer constar la aportación isleña tanto en la etapa colonial

2 Razones de espacio dejan fuera una visión más amplia del contexto investigador español en relación, por ejemplo, con América. Esta adquirió, como se sabe, una situación de privilegio durante muchas décadas debido a diversos motivos (Catalán 1974: 43, 100, 111). En este contexto, así pues, habría que situar la especial atención de Pérez Vidal hacia todo lo americano. Para algunos aspectos bio-bibliográficos del autor, véanse López y Cea (1987/2007) y Díaz Alayón (1993). 
como en la época de la independencia. Pero si los canarios influyeron en la gestación de las sociedades virreinales y, especialmente, en el terreno urbanístico, demográfico y socioeconómico de los siglos XVIII al Xx, no menos es lo que podría denominarse una "influencia de vuelta": todo aquello que el emigrado ha introducido en las Islas, donde ha arraigado con mayor intensidad que en otras regiones españolas. El comercio trajo papas, boniatos o batatas, tomates, maíz y tabaco, además de nopales o tuneras, pimenteros peruanos, cueros o cacao. También proporcionó nuevas frutas como las papayas, mangas, chirimoyas, aguacates, piña tropical o guayabas, consideradas como "frutas tropicales" en muchos mercados peninsulares y que, sin embargo, en las Canarias pierden ya ese carácter exótico y se han adaptado, sin duda, por las similares condiciones climáticas de las Islas con algunas áreas del Caribe. Canarias aportó vinos y vides, quesos, harina, animales (gallinas, cabras, carneros, ovejas, cabritos, camellos, cerdos), simientes, pescado y carne salados, tocino, conchas coloradas, plátanos, ñames, almendras, miel, agua, leña... En el terreno musical se hacen habituales los "puntos cubanos", "guajiras", las "habaneras" o "corridos mejicanos"; mientras que el arte ofrece hermosas muestras de orfebrería, ornamentos de variado tipo, imaginería y arquitectura religiosas junto con la doméstica. Costumbres y modismos lingüísticos son también reconocidos aquí y allá con bastante facilidad, si bien es cierto que en muchos casos no sabemos quién importó o quién exportó a uno y otro lado del Atlántico (Medina López 1999). En el terreno lingüístico es notorio el número de trabajos que ha visto la luz en ambas orillas atlánticas; investigaciones en las que bien de forma directa o bien a través de fuentes indirectas, o de manera referencial, Canarias está presente en América y América lo está en las Islas. $\mathrm{O}$ ambas forman parte de un mismo devenir histórico en un proceso continuo de mutuas interrelaciones a través de los últimos cinco siglos ${ }^{3}$.

Pero así como escaso y fragmentario era el status quaestionis sobre el español canario y sus relaciones con América en la década de los años cincuenta del siglo xx, lo cierto es que la visión que podemos trazar hoy en día es radicalmente opuesta. Y eso que una total comparación entre Canarias y América no está exenta de algunos planteamientos de orden teórico-práctico y documental. Así, nos encontramos con la propia consideración del concepto de "español atlántico", al que añadiríamos la diversidad sociolingüística americana, el escaso conocimiento en materia lingüística que se tiene de

\footnotetext{
Véase el nuevo diccionario de las relaciones léxicas canario-americanas de Corrales y Corbella (2010).
} 
algunas zonas, al tiempo que la desigual huella americana en las Islas o de lo canario en América, circunstancias todas que de un modo u otro muchas veces hacen insegura una total o parcial comparación e interrelación de las dos realidades (Samper Padilla 1994: 1175-1178). Y por todo ello, y cada vez más, se demanda un expurgo de la documentación histórica y de variadas fuentes, porque solo un análisis pormenorizado de dichos documentos (examinados con fines lingüísticos) pondrá de relieve -hasta donde sea posible- los caminos de la lengua, de las modas y de los usos que llegaron a triunfar en las dos orillas o de lo que en unas zonas arraigó y en otras, por el contrario, cayó en el olvido y en desuso ${ }^{4}$. Canarias y América, en fin, entran de lleno en el espacio asignado a los centros irradiadores de los modelos de habla en el mediodía peninsular español, constituyendo así -en buena medida- una norma meridional-atlántica.

\section{EL PANORAMA HISTÓRICO EXPUESTO POR JOSÉ PÉREZ VIDAL}

En el artículo de Pérez Vidal de 1955 se observa desde el principio la agudeza de su análisis a través de las ciento trece páginas de las que consta su trabajo. El punto de partida es el hecho histórico y el enclave de las Canarias en la época del descubrimiento americano, en relación con los viajes de Colón ${ }^{5} \mathrm{y}$, en particular, con la participación "variada y vigorosa" de los canarios en la conquista y colonización, con la aportación de animales, la caña de azúcar ${ }^{6}$, el plátano y, posiblemente, el ñame. En palabras del maestro palmero:

Este comercio y el paso casi obligado de las flotas, con los consiguientes relatos de los viajeros, forzosamente habían de estimular la curiosidad y el ansia de aventuras de los isleños. El fuerte tirón que no sólo España,

\footnotetext{
4 Como ocurre, por ejemplo, con las zonas voseantes y las tuteantes en América. Vid., además, el trabajo lexicográfico de Corrales y Corbella (2001) que contiene numerosos ejemplos de documentos históricos.

5 "Las Canarias hicieron las veces, pues, de formidable trampolín para el gran salto" (Pérez Vidal 1955: 92).

6 Pérez Vidal toma una cita de G. Fernández de Oviedo en su Historia general y natural de las Indias, Madrid, 1851, lib. vIII, cap. I, XI. (Pérez Vidal 1955: 95, nota 7).
} 
sino toda Europa, sintió hacia el Nuevo Mundo, se experimentó más enérgicamente en Canarias, situadas a mitad del camino de aquellas tierras en que se esperaba encontrar los más grandes tesoros (Pérez Vidal 1955: 99).

José Pérez Vidal manifiesta -según los datos conocidos a mediados de la década de 1950-, que el contingente canario que marchó a América no fue, en realidad, "muy considerable", máxime si se tiene en cuenta que en las Islas hacia 1492 tampoco se había terminado el proceso de anexión a la corona castellana. Verdaderamente las páginas dedicadas a la inicial población canaria a América (entre cifras, fuentes y autores que han tratado el tema) recuerdan la polémica sobre la configuración del español americano y su relación con el español meridional (andaluz) o con el desarrollo autónomo del mismo. Pérez Vidal trae también a colación, aunque con intereses diferentes, los nombres de Rufino José Cuervo, quien habla solo de un canario en sus fuentes ${ }^{7}$, Pérez Bustamante, Lorenzana y González García, quienes señalan también la presencia de tres individuos (con datos de 1928), frente a los de Henríquez Ureña $(1930)^{8}$, que en una de sus emblemáticas obras registra la aportación de cuatro canarios ${ }^{9}$. A todo esto apostilla Pérez Vidal su visión crítica por los métodos empleados en la identificación de pasajeros a Indias, la irregular distribución de los mismos en América y advierte que el conocido Catálogo de Pasajeros no resulta de interés para Canarias porque no expresa el movimiento migratorio insular, puesto que este salía directamente desde las Islas hacia América y, por tanto, los pasajeros no tenían la obligación de ser registrados en la "Casa de Contratación" sevillana. Todos estos datos, más los de Pérez Bustamante (1941) y Rodríguez Arzúa (1947), hacen pensar a Pérez Vidal en la "real" importancia de la emigración canaria hacia América,

Cuervo se basa en un registro de 160 nombres de individuos de procedencia conocida que aparecen en los datos de López de Gómara, Juan de Castellanos, el obispo Lucas Fernández de Piedrahita y Oviedo y Baños. Cuervo, que será citado por Pedro Henríquez Ureña años después, señaló que "La historia y la filología están conformes para probar que los primeros pobladores de América representaban todas las comarcas de la península ibérica [...] Comprobación palmaria de estos hechos históricos ofrece el habla americana, en la cual se hallan mezclados términos y locuciones de toda la península ibérica". Cuervo, no obstante, es consciente de la escasez y fragilidad de sus datos. Vid. Cuervo (1901: 41-42).

8 En este trabajo, el autor dominicano ve poco sólida la presencia canaria en los primeros años de la conquista: "Las Islas Canarias, a las que infundadamente se suele atribuir gran papel en la primitiva colonización de América, dan apenas el 0,4 por 100 [...] Las Canarias envían apenas cuatro personas".

9 Aunque como bien señala Pérez Vidal (1955: 101), las cifras de Henríquez Ureña aumentan hasta 54 canarios (de un total de 13.948 personas de variada procedencia peninsular) para el período comprendido entre 1492 y los primeros años del siglo XVII. 
a lo que añade el destacable papel jugado por las salidas ilegales, tanto de peninsulares como de canarios, evitando así los controles migratorios, los trámites burocráticos y la exención de pagos y tributos para viajar al nuevo continente $^{10}$. Y esta realidad del siglo XVI la extrapola Pérez Vidal a las circunstancias de mediados del siglo xx:

Hasta nuestros días, la corriente migratoria de Canarias a América ha sabido salvar todos los obstáculos. Las aduanas de salida, el inconveniente de los trasatlánticos tan estrechamente vigilados, las aduanas de llegada, todas las trabas y vallas para impedir la emigración las ha sorteado el emigrante canario con este tesón que tan bien sabe disimular el isleño bajo la dulzura de su carácter. En frágiles barquichuelos han salido estos últimos años grupos y grupos de isleños con rumbo a Venezuela. Las sombras de la noche han asegurado en todo tiempo la marcha clandestina (Pérez Vidal 1955: 103).

Otro de los aspectos que pone de relieve el examen de Pérez Vidal es la cualificación social que tenían los "canarios" que pasaron a América en la primera mitad del siglo XVI y que formaron parte, en este sentido, de los orígenes de "lo americano". A la inicial aportación de marineros y soldados, hubo también agricultores, artesanos, hombres de paz y asiento, además de maestros y oficiales azucareros. En la segunda mitad del xvi asistimos a la creciente llegada de colonos, fundadores y gente estable, entre las cuales destaca la salida en "bloques de familias". Eran agricultores destinados a trabajar las tierras y a crear nuevas comunidades o repoblar aquellas que, como las islas de las Antillas, estaban siendo peligrosamente abandonadas en favor del continente. Similar situación debió darse en Canarias, que estaban cada vez más desérticas ante la petición de emigrar a Indias, lo que obligó a que el rey Felipe II prohibiera en 1574 la salida de los vecinos ${ }^{11}$.

Desde mediados del siglo XVI, pues, la emigración isleña a Indias debió de ser cuantiosa. Así lo hace suponer, además, el escrito que el Juez de Gran Canaria, Pedro de Escobar, alarmado de la despoblación de la isla,

10 La emigración legal también fue analizada por Pérez Vidal, con amplio aparato crítico, al referirse a las expediciones de Nicolás Ovando (1502), Alonso Quintero (1504), Solís (1515), Lope de Sosa (1519), Luis de Anday (1525), Francisco Montejo (1526), Caboto (1526), Pedro de Mendoza (1535) o Pedro de Lugo (1536), entre otros.

11 La inicial prohibición duró poco tiempo y el fomento de la emigración no se hizo esperar ante la peligrosa extensión de los extranjeros en las colonias españolas, lo que provocó la salida regular de una intensa corriente migratoria de isleños. Con destino a Cumaná, Campeche, las Antillas Mayores, Florida, la Louisiana, Guatemala, Cuba, Venezuela y otras a lo largo del XVII y XVIII. 
dirige a Felipe II. Él ve con intranquilidad que la isla se queda desierta e indefensa frente a los "navíos de luteranos y otros enemigos" (Pérez Vidal 1955: 114).

El capítulo II del trabajo de Pérez Vidal está dedicado a lo que él denomina "El esquema de la obra de los canarios en América", deteniéndose en la corriente migratoria que ininterrumpidamente ha venido sucediéndose desde los primeros viajes colombinos hasta nuestros días ${ }^{12}$. Su panorámica esboza, pues, los isleños que han destacado en la vida americana, siendo consciente, además, de la gran masa anónima colonizadora. Y como en toda empresa de este tipo, comienza dando referencias y nombres de militares ${ }^{13}$ y mandos que ocuparon diferentes destinos y obligaciones, como virreyes, gobernadores, capitanes o corregidores. De igual forma, destacan los canarios que defendieron la soberanía española cuando ya empezaban los primeros brotes de la emancipación americana ${ }^{14} \mathrm{o}$ los que, por el contrario, sintiéndose hijos de una nueva realidad, lucharon por la independencia ya en la centuria decimonónica ${ }^{15}$. Pero si intensa fue la obra militar, no lo fue menos la huella de los canarios en el terreno evangelizador. Y aquí Pérez Vidal (1955: 135 y ss.) cita en primer lugar al conocido y venerado P. José de Anchieta, apóstol del Brasil, al P. José de Arce y Rojas, a Fr. Pedro de Béthencourt (fundador de los bethlemitas), al obispo de Cartagena Manuel de Sosa Béthencourt, Francisco José de Palencia, deán de Guatemala, Francisco Matos Coronado, obispo de Yucatán, y tantos otros.

La visión dada por José Pérez Vidal sobre la huella canaria en América durante el período colonial $-\mathrm{y}$ especialmente la que se refiere a las personalidades que destacaron tras la independencia- es bastante exhaustiva. Y así sobresalen aquellos que lo hicieron en el terreno de las letras y las artes como escritores, los que ocuparon cargos académicos, como Valerio Fernández Ferraz (decano de la Facultad de Filosofía y Letras de la

12 Este "hasta nuestros días" hay que referirlo a la década de 1950; la situación actual, como se sabe, es muy distinta.

13 Como Agustín Delgado, Antón García (llamado Antón del Guante), Luis Perdomo, Juan el Canario, Baltasar de Castilla, Alonso de Alvarado, Sebastián de Castilla, Francisco Bahamonde Lugo, Antonio Peraza de Ayala Castilla y Rojas, Pedro de Ponte, Diego de Ponte, Diego de Nava y Grimón, Pedro de Nava, Juan de Mesa y Lugo, Francisco Dávila Orejón, Pedro Benítez de Lugo, Antonio Benavides, Antonio Porlier y Sopranis.

14 Como son Domingo Monteverde, Francisco Tomás Morales, Gaspar Pinto Vandewalle, Alonso de Castro y Vinatea, Pedro Verdugo y Massieu, Pedro Díaz Felipe y Edmundo Amador Bustamante.

15 Fernando Key y Muñoz, Luis Báez, Francisco Escalada, Francisco Aguilar y Leal, muchos de los cuales desempeñaron cargos de relevancia en las nuevas repúblicas. 
Universidad de La Habana), fundadores de diarios, directores de museos y de imprentas nacionales, catedráticos de historia de la literatura española y de latín y periodistas, amén de otras muchas actividades. Resaltan, en este sentido, las fundaciones de periódicos y gacetillas por toda la geografía donde la colonia canaria fue importante. El proceso emancipador de las tierras americanas trajo como consecuencia para la comunidad canaria en América la necesidad de mantenerse informadas y conectadas allí donde el peso social y cuantitativo de este colectivo así lo exigía. Y la comunicación se produjo a través del nacimiento de numerosos periódicos y gacetas que -hechos por canarios para la comunidad canaria- cumplían con el objetivo de informar acerca de cuestiones de interés para el emigrante, dar noticias de las Islas o llevar a cabo análisis y comentarios de diversa índole. Junto con las publicaciones más o menos periódicas empezaron a nacer también las distintas "asociaciones canarias" o, más modernamente, los "hogares canarios" o "centros canarios" que desarrollan, todavía hoy, una intensa labor cultural y social y siempre mantienen vivo el recuerdo del Archipiélago ${ }^{16}$.

Pero si los datos de Pérez Vidal hacen referencia a los canarios que destacaron en América, por la circunstancia de ocupar algún puesto de relevancia, no lo es menos el interés en poner de manifiesto la labor callada de "la masa anónima de isleños". Y así se hace en las páginas dedicadas

16 Pérez Vidal (1955: 138) da noticias de El Mencey, El Eco de Canarias, La Revista de Canarias, El Guanche, Canarias, Patria isleña, Cuba y Canarias. Un año más tarde, Fernández (1956-57) se ocupa de este particular y ofrece unas notas sobre los periódicos canarios en América. Mucho tiempo después, un listado provisional ofrecido por Cabrera Déniz (1991: 331-332) muestra un conjunto de títulos de periódicos canarios en América que corrió desigual suerte. Así, en Buenos Aires surgen en el xx los siguientes: Canarias (1913; 1917-1946), El Guanche (1944-1946) у C. A. C. (1960). Cuba es el país con mayor número, alguno de los cuales son: El Mencey (1864), El Correo de Canarias (1882), El Eco de Canarias (1883), La Voz de Canarias (1884-1886), Canarias (1888), Revista de Canarias (1890), La Colonia de Canarias (1891-1893), Las Afortunadas (1893-1899; 1907), El Heraldo de Canarias (1909), Cuba y Canarias (1907; 1912), Islas Canarias (1908-1917), El Guanche (1924), La Patria isleña (1926), Hespérides (1930), Tierra Canaria (1932), Boletín de Cuba y Canarias (1938), Canarias en Cuba (1946), editada la gran mayoría en La Habana. Uruguay también contó con revistas como Vida Canaria (1928), s. I C. (1954), Hespérides (1955-1956) o El Drago (1960-1964) que vieron la luz en Montevideo. Por su parte, en la capital venezolana salieron El Guanche (1898), Canarias (1954-1955), Archipiélago Canario (1968), Canarias Gráfica (1971-1973), Hogar Canario-Venezolano (1974-1975) y Siete Islas (1978). Cfr. también las páginas que, para Cuba, escribe Hernández García (1981: 470-476) con carácter general. 
a la colonia canaria y su papel protagónico en la fundación de ciudades, pueblos y aldeas ${ }^{17}$.

\section{EL PANORAMA LINGÜÍSTICO EXPUESTO POR JOSÉ PÉREZ VIDAL}

El conocimiento tanto del folclore canario como de los aspectos lingüísticos era escaso en los años en que nuestro autor debió escribir su largo trabajo, lo que con cautela le lleva a decir que:

Exponer ahora sistemáticamente los contactos canario-americanos en la lengua y en el folklore resulta demasiado prematuro. Falta todavía completar una labor previa y fundamental: la de recogida y estudio de materiales lingüísticos y folklóricos en América y Canarias (Pérez Vidal 1955: 164).

$\mathrm{Y}$ en efecto, así era. Pocas referencias, alusiones dispersas y algo de diletantismo (salvo las honrosas excepciones) había todavía en el año en que se publican estos materiales. Solo tiempo después aparecerán las primeras monografías y los trabajos fundamentales que abrirán, también, un camino fructífero de investigación, análisis e inventario del habla canaria ${ }^{18}$. Pero

17 En Santo Domingo (San Carlos, San Rafael de la Angostura, Santa Bárbara de Samaná, Sabana de la Mar, Montecristi, Puerto Plata), Puerto Rico (Candelaria), Cuba (San Carlos de Nuevitas, Matanzas, Madruga), en Texas (Galveston, Valenzuela), la Louisiana (St. Bernard), Venezuela (Candelaria), Uruguay (Canelones) y el Perú, entre otras.

18 Téngase en cuenta, por ejemplo, que El español hablado en Tenerife de Manuel Alvar, no aparecerá hasta el año 1959, publicado en Madrid como Anejo LXIX de la Revista de Filología Española. El propio Pérez Vidal hará una reseña de esta monografía que saldrá en la RDTP, XV (1959), pp. 540-542. Estamos ahora ante la primera monografía sobre un habla canaria. De su importancia y de los caminos que trazó es suficiente hoy la realidad investigadora desde y para el Archipiélago. Se trata de una de las zonas mejor y más estudiadas del mundo hispánico. Los materiales lingüísticos de otro insigne palmero, Juan Régulo Pérez, aunque recogidos en diversas encuestas en los años 1946, 1947 y 1948 no verán la luz hasta 1968, fecha en la que defiende su tesis doctoral titulada El habla de la isla de La Palma (Canarias) en la antigua Facultad de Filosofía y Letras de la Universidad de La Laguna. No excluyo, por supuesto, los trabajos de Juan Álvarez Delgado, Max Steffen, D. J. Wölfel o el propio Régulo Pérez, entre otros, con direcciones hacia el sustrato aborigen, las relaciones con otros dominios lingüísticos o los llamados a explicar las peculiaridades del léxico canario. Otros estudios señeros de esta época son los de Diego Catalán, que serán publicados a partir de 1959, y al que se le debe la 
cabe hacer una consideración fundamental para entender la concepción de Pérez Vidal de la real aportación canaria a las tierras americanas, y es la que se refiere al origen del contingente humano que pobló el Archipiélago en los primeros años y su posterior influencia en América. En este sentido, Pérez Vidal (1955: 164) llama la atención de un hecho incuestionable y es que "gran parte de los pasajeros embarcados en Canarias para América en la primera mitad del siglo XVI no debió de estar constituida por naturales de las islas", sino que mayoritariamente provenían de Extremadura y Andalucía (Cádiz, Sevilla y Huelva), lo que en los años cincuenta del xx significaba avalar la tesis de los defensores del andalucismo del español americano. Por eso escribe Pérez Vidal (1955: 165) que "Tomen nota, especialmente, quienes discuten sobre el andalucismo de América". La referencia, en este sentido, se ve argumentada por una cita de Menéndez Pidal:

A pesar de las afirmaciones contrarias que sobre cálculos de dudosa exactitud se han hecho en estos últimos años, no han perdido totalmente su valor las afirmaciones que don Ramón Menéndez Pidal hizo en 1917 al tratar de La Lengua española en "Hispania" (California), I, pág. 5: "El grueso de las primeras emigraciones salió del Sur del reino de Castilla, es decir, de Andalucía, de Extremadura y de Canarias" (Pérez Vidal 1955: 165 , nota 1$)$.

Para una segura comparación e influencia entre las dos realidades, es decir, entre la canaria y la americana, Pérez Vidal señala que aunque el camino no está exento de dificultades, hay que separar lo que ambos mundos comparten, los parentescos y coincidencias que nacen del tronco común "matriz" del español, además de prescindir de los fenómenos folclóricos y lingüísticos que se hayan podido desarrollar de forma paralela en Canarias y en el Nuevo Mundo. Es entonces cuando llegará el momento de saber lo que hay de canario en América y lo que de América se encuentra en el Archipiélago.

Pero, ¿de qué nos informa Pérez Vidal?, ¿qué es lo que conocía de las coincidencias canario-americanas? Para empezar hace notar que los rasgos en el terreno lingüístico deben analizarse teniendo en cuenta tanto aquellos que pueden explicarse por influencia andaluza como por el resultado de un desarrollo que experimentó la lengua, de forma coincidente y simultánea,

acuñación del término "español atlántico", expresión que ha tenido una gran difusión en el ámbito lingüístico. 
entre Andalucía y América y, por supuesto, en el puente entre ambas ${ }^{19}$. Es evidente que la escasez de datos, de la que ya había advertido nuestro autor, le hace ser bastante precavido en afirmaciones y descripciones de mayor enjundia como las llevadas a cabo en la primera parte de su estudio, en la que se advierte un fino análisis textual, histórico y documental, además de las numerosas fuentes consultadas. Las coincidencias en el terreno fonético son las consabidas; es decir, la constatación de la reducción del antiguo subsistema de las cuatro sibilantes medievales que dieron lugar al seseo $^{20}$; las realizaciones aspiradas de la [-s] implosiva o final de sílaba en una [-h] del tipo [de ${ }^{\mathrm{h}}$ pwéh $]$ 'después', [mi' ${ }^{\mathrm{h}} \mathrm{mo}$ ' 'mismo'; la aspiración de la antigua $f$ - $>$ [h-] inicial latina en los ambientes rústicos o la "tendencia a reducir la $j$ a una aspiración sorda, pronunciada con poca fuerza" (Pérez Vidal 1955: 167). Vagas son también las referencias que dedica a la gramática común a ambos lados del Atlántico. Así, se nombra el abandono del vosotros en favor de ustedes, los usos de los diminutivos, particularmente el de la forma -ito, además del aumento de las frecuencias también de la perífrasis compuesta por ir + gerundio (voy a ir cavando), frente al "normal" voy a cavar.

La sección más extensa y rica del trabajo de Pérez Vidal en cuanto a los aspectos lingüísticos se refiere es la que tiene que ver con los comentarios léxicos, a los que, por otro lado, dedicó amplios y enjundiosos trabajos. Así, señala la abundancia de palabras y acepciones "arcaicas" que son propias de la lengua popular: candela, demorar, contesta, trulla, componte 'castigo', vellón 'moneda', etc. Como otros muchos autores contemporáneos -y señala como referencia de nuevo a Menéndez Pidal-, Pérez Vidal (1955: 168) cree que "La mayor proporción y extensión de las formas arcaicas da al español de Canarias y al de América un cierto matiz de rusticidad que en la Península apenas se encuentra fuera del ambiente aldeano". Sin embargo, de los vulgarismos indica que estas manifestaciones aparecen por igual en el habla popular española: dispierto, sospiro, prencipio, güérfano, güeno, agüelo, traíba o diba. Mayor extensión dedica a las voces marineras o náuticas, sobre las que escribirá algunos artículos ${ }^{21}$ a lo largo de su vida, y que se justifican, lógicamente, por la situación geográfica de las Islas, las corrientes

19 Parece moverse entre los defensores del andalucismo y los que creen en un desarrollo autónomo de la base lingüística del español americano, sobre todo si se contrasta con su afirmación expuesta más arriba.

20 Pérez Vidal (1955: 167) no habla de seseo propiamente, sino de la fusión de las cuatro sibilantes $s, s s, c ̧$ y $z$ en una $s$ de articulación muy variada, pero más cerca, por lo general, de la $s$ andaluza que de la castellana y norteña.

21 Vid. a Díaz Alayón (2005), quien compila el más amplio repertorio bibliográfico publicado sobre nuestro autor. 
migratorias con América, el origen marinero de muchos colonizadores o las condiciones de vida cerca del mar en varios enclaves americanos. Son numerosos los términos marineros comunes en Canarias e Hispanoamérica, entre otros, aboyar 'flotar', botarate 'derrochador', abrirse 'marcharse', balde 'cubo', botado 'tirado', empatar 'empalmar, juntar una cosa a otra', rebencazo 'golpe dado con cualquier objeto parecido al rebenque', toletazo 'golpe dado con un palo', etc.

Las Canarias aportaron a América, en el terreno del léxico, la voz de origen guanche gofio ${ }^{22}$, atestiguada ya en 1836 en el Diccionario de voces y frases cubanas de Esteban Pichardo. Es esta la única palabra que reseña Pérez Vidal, si bien hace notar que esta escasez se debe a que en el propio español insular pocas son las supervivencias de las lenguas indígenas. Mayores son, por el contrario, las coincidencias que llegaron a América a través del Archipiélago, donde se produjo una adaptación ${ }^{23}$. Tal es lo que ocurre con el léxico azucarero -de claras resonancias canarias-, al igual que el vocabulario referido a la dulcería popular que tan ligada estaba a los ingenios de azúcar, entre los que sobresalen las conservas almibaradas, con voces como rapadura o raspadura. Las Canarias también llevaron el ñame y el plátano, así como la picuda o bicuda, con resultados en Colombia, Cuba, Puerto Rico y Venezuela ${ }^{24}$.

Especial mención merece la parroquia de St. Bernard (en la Louisiana estadounidense), a la que Pérez Vidal dedica unas cuantas páginas con abundantes ejemplos. La inicial población de esta comunidad, de origen canario aunque luego interrumpida, dejó sus huellas en el plano fonético, morfológico y léxico. Aunque no cita la procedencia de los mismos, presupongo que la referencia al estudio de MacCurdy es el origen de su información ${ }^{25}$. El apartado lingüístico se cierra con unas palabras que resultan ilustrativas de lo que Pérez Vidal -a pesar de su fragmentaria información

22 Vid. Díaz Alayón (1991: 718) y Corrales y Corbella (2010), s. v.: gofio.

23 A este mismo proceso se refirió, décadas después, Alvar (1969).

24 Pérez Vidal (1955: 176-177) plantea que algunas voces que han sido consideradas de invención americana han llegado al Nuevo Mundo a través de Canarias, tal y como parece que fue, en efecto, el caso de la voz picuda, atestiguada en los Acuerdos del Cabildo de Tenerife en un acta del 26 de enero de 1498, según informan Corrales y Corbella (2001) en su monumental diccionario, s. v.: picuda. La voz bicuda, de origen portugués, es la más antigua y se mezcla muy pronto con la castellana. La geografía de este término es variada y, dada la antigüedad de la documentación canaria, puede pensarse, como ya sugirió Pérez Vidal, que de las Islas pasó a América. Vid. también Pérez Vidal (1970 y 1973).

25 En la p. 91 dice: "MacCurdy señala la afinidad, tanto fonética como morfológica, existente entre el dialecto de St. Bernard y la lengua popular de Andalucía y de las Antillas". No obstante, Pérez Vidal sí que menciona al hablar de la colonización del sur de los EE.UU. 
en este terreno- aventuraba acerca de la influencia del habla canaria en la constitución y posterior desarrollo del español "popular" americano:

No pretendo, en resumen, dar excesiva importancia a la influencia isleña en la lengua popular hispano-americana. El español de Canarias no es sino una modalidad tardía resultante de la fusión de elementos heterogéneos, entre los que predominan los procedentes del Sur y del Oeste de la Península. Pero, aun limitando muchos su importancia, debe ser tenido en cuenta en los estudios sobre el español popular de América. Puede resultar de esclarecedora eficacia para explicar algunas de las modalidades de éste (Pérez Vidal 1955: 182).

Y cierto es que así fue tiempo después. Fundamentales han sido los trabajos llevados a cabo a partir de la década de los años cincuenta sobre el español de las Islas Canarias para poder también trazar las relaciones de ida y vuelta de la lengua a través del largo océano. La descripción del habla de las Islas es prácticamente total hoy en día. La existencia de la cartografía lingüística también abarca a todo el Archipiélago, los estudios sobre las lenguas aborígenes canarias han experimentado un notable incremento en número y en calidad, la huella portuguesa está trazada, las relaciones con otras variedades del español o con otros dominios románicos también han sido puestas de manifiesto y los análisis sincrónicos de multitud de fenómenos (fonéticos, gramaticales y léxicos), en definitiva, han hecho que conozcamos hoy con suficiente rigor científico los fundamentos en los que se asienta el habla insular. Por todo ello, las palabras de Pérez Vidal escritas hace décadas tienen ahora una segura confirmación. Si bien es cierto que, todavía, quedan muchos asuntos por esclarecer en la lengua común de Canarias y América. Las Antillas (Cuba, Santo Domingo y Puerto Rico) cuentan con numerosos trabajos en esta línea, y lo mismo ocurre con Venezuela y Uruguay; y no digamos el dialecto canario de la Louisiana, que se ha convertido, con el transcurrir de los años, en todo un "clásico" de las relaciones canario-americanas. 


\section{EL PANORAMA LITERARIO EXPUESTO POR JOSÉ PÉREZ VIDAL}

Si las dificultades presentadas por nuestro autor para establecer una segura comparación lingüística entre la realidad canaria y la americana eran complejas, tal y como él mismo manifestó, las que conciernen al terreno literario son, a su juicio, aún mayores. Y la razón estriba, en aquellos años una vez más, en la inexistencia de una "literatura tradicional canaria con rasgos bien definidos" (Pérez Vidal 1955: 182). Esto es lo que explica, en buena medida, que las páginas dedicadas a la poesía tradicional sean las más escasas dentro de este estudio. No obstante, y a pesar de esta carencia, las Islas sí que han servido de plataforma de acogida y expansión de todo aquello que llegaba de la Península. El arcaísmo poético, en este terreno (tal y como puso de manifiesto para la lengua), parece ser un denominador común.

La estructura familiar que emigró a América desde las Islas sirvió de base para el traspaso también de los viejos metros arraigados en la poesía tradicional, tales como el romance y sus antiguas versiones ${ }^{26}$. En este sentido, Pérez Vidal se detiene en los parecidos del conocido romance titulado "Blanca Flor y Filomena", cuya versión insular es similar a las que se dan en Puerto Rico y Santo Domingo; el que lleva por título "La Infanticida", con idénticas referencias en Puerto Rico, a diferencia de las otras variantes peninsulares. Coinciden también las versiones del romance "El mal de amor" entre Canarias y Cuba, y es forma muy parecida con la versión portuguesa.

Sean o no casuales, o el resultado de causas comunes, lo cierto es que en América, a juicio del investigador palmero, hay muchas similitudes que están "perfectamente explicadas por la procedencia canaria de la versión americana" (Pérez Vidal 1955: 193). Y un caso de estos es el romance "La esposa infiel", atestiguado en su versión canaria por Pérez Vidal en la Villa de Mazo (La Palma). Esta historia tiene sus correlatos similares en Cuba de labios de una descendiente de canarios y en México.

También están los llamados cantos de cuna, entre los que sobresale el popular arrorró, para el que existen idénticas formas en Cuba, Venezuela o Argentina, además de las variantes documentadas en toda la geografía

26 Es destacable el aparato crítico y referencial que señala Pérez Vidal (1955: 189-190, nota 32) en este aspecto, sin duda como gran conocedor de la tradición lírica popular y, en especial, del romance. 
peninsular $^{27}$ y en donde la cadencia o melodía musical —unida a las diferencias fonéticas entre una región y otra- explican las variadas fórmulas del arrullo infantil: arrorró, a laroro, al ronrón, a laruru, arruarru, arrurrú, rurrú, al runrun... Otro aspecto que despierta el interés de Pérez Vidal es el de las adivinanzas. Así, advierte de la titulada "Adivinanza de la nave", que aparece ya desde el antiguo Libro de Apolonio, pero la versión en la que la nave nace en el monte solo la recoge en Canarias y Puerto Rico. Como puede observarse, el conocimiento de Pérez Vidal sobre el romancero palmero y el canario en general es cabal en éste y en otros trabajos. Su labor se extendió no solo a la recopilación y estudio particular de las Canarias, sino también a su procedencia, adaptación y recreación insulares, y a su exportación a América. Como señala Trapero:

De fundamental hay que calificar la aportación de Pérez Vidal al conocimiento del romancero tradicional de Canarias, y más concretamente de la isla de La Palma. Gracias a muchos y sucesivos estudios conocemos hoy bastante bien no sólo la tradición romancística palmera, sino algunas de las características comunes generales del romancero canario, como el del fenómeno de los estribillos romancescos, por ejemplo (Trapero 1993: 65).

\section{AMÉRICA EN OTROS TRABAJOS DE JOSÉ PÉREZ VIDAL: PANORÁMICA}

Escribía Trapero (1993: 64) en un artículo sobre la obra de Pérez Vidal y el romancero que el tema de Canarias y América está repartido por toda su producción científica. Y esto es así si se tiene en consideración que ya desde la década de los años treinta del siglo xx empieza a publicar artículos, reseñas y comentarios de diversa índole que ponen de relieve la especial predilección del autor palmero por las cosas de Canarias y sus posibles vínculos históricos, etnográficos, culturales, folclóricos, lingüísticos y, en definitiva - de tradiciones y cultura populares- con América.

27 Destaca la referencia bibliográfica que acompaña a los ejemplos de Pérez Vidal (1955: 183, nota 24): una cita de R. Rodríguez Marín, Cantos populares españoles, Sevilla, 1882. 
De 1932 es su estudio sobre el almirante Díaz Pimienta y la piratería en América a mediados del siglo XVII, al que seguirán varios más sobre este personaje (Pérez Vidal 1933, 1934, 1976 y 1982). Francisco Díaz Pimienta nace en Tazacorte (La Palma) en 1594 y llegó a ser General de la Real Armada de Las Indias, además de constructor naval en La Habana. Pérez Vidal traza la semblanza de este personaje y su destacado protagonismo en América, donde defendió la isla de Santa Catalina, llamada por los ingleses Providencia. En el primer librito que publica Pérez Vidal (1933), se advierte la humildad investigadora que caracterizó toda su obra, la cual no supone, por supuesto, restarle importancia y enjundia algunas. En la "Advertencia preliminar" de este opúsculo señala:

El dar a la estampa estos oscuros documentos recogidos despaciosamente, por llenar ratos de ocio, en archivos de Madrid y Sevilla, y que ahora, por indicación y empeño de un venerable amigo, desempolvo en público, no encierra otra pretensión que la de ínfima a que puede aspirar una publicación de esta clase: salvar viejos papeles de cualquier accidente que los destruya y facilitar su conocimiento a las pocas personas a quien pueda interesar ${ }^{28}$ (Pérez Vidal 1933: 4).

En 1943 publica un pequeño artículo en la Revista de Historia de La Laguna sobre el poema más antiguo de la literatura cubana (Pérez Vidal 1943). Se trata de una comunicación al director de la revista, en la que le informa de una reciente conferencia impartida en La Habana sobre el poeta canario Silvestre de Balboa Troya y Quesada, quien escribe un poema en octavas reales titulado Espejo de Paciencia.

También a esta época (Pérez Vidal 1945) pertenece la semblanza biográfica del palmero D. Valeriano Fernández Ferraz, que fue catedrático de árabe en la Universidad de Madrid en 1869 y un conocido seguidor de las ideas krausistas ${ }^{29}$. Muchas décadas después (Pérez Vidal 1988), vuelve sobre la familia Fernández Ferraz al trazar la experiencia vital de Juan Fernández Ferraz, persona nacida en Santa Cruz de La Palma el 30 de marzo de 1849.

Como ya se ha visto páginas arriba, el tema de los ingenios de azúcar siempre le interesó al maestro palmero. Y así se acercará en varios trabajos relacionando la Península Ibérica, Canarias y América desde una perspectiva eminentemente histórica. En todos destaca la cultura de la caña de azúcar y

29 Vid. Pérez Vidal (1986). 
de su contorno industrial, establece el origen del cultivo, introducción de la caña, expansión de la misma en Canarias y América, etc. ${ }^{30}$

La poesía tradicional canario-americana la encontramos en varios trabajos. Uno de ellos (Pérez Vidal 1944) aborda los diferentes temas de la poesía tradicional canaria y destaca el del mar, que lo relaciona con la isla de Puerto Rico. El mar es una realidad constante y fundamental en el paisaje de las Canarias y en el de la isla del Caribe. Dice al respecto que lo primero que llama la atención de la literatura popular canaria es la gran cantidad de cantos importados que esta posee.

Un libro fundamental de Pérez Vidal (1959) es el dedicado al tabaco, donde de forma pionera pone de manifiesto la génesis de este producto, su expansión, producción y vocabulario. Traza de forma ejemplar la participación de España en el descubrimiento del tabaco y su presencia en la historia tabaquera mundial. La primera parte de esta larga monografía (329 páginas) está dedicada a América. Otros trabajos, en fin, versan sobre distintos temas, como la devoción religiosa a ambos lados del Atlántico (tal es el caso de Santa Ana y Nuestra Señora de los Remedios, que publica en el Diario de Avisos de Santa Cruz de La Palma el 2 de julio de 1955); sobre los portuguesismos que se llevaron a América desde Canarias (Pérez Vidal 1960) o el dedicado a la poesía tradicional canaria en México (Pérez Vidal $1984 / 1991)^{31}$. Se trata de un estudio basado en los datos suministrados a Pérez Vidal por el folclorista mexicano Vicente T. Mendoza, quien consideró que dada la naturaleza de los materiales recogidos en diversas encuestas en México, y puesto que una de sus entrevistadas resultó ser natural de $\mathrm{La}$ Orotava (Tenerife), prefirió que fuera un investigador canario el que analizara los datos compilados. Pérez Vidal, después de muchos años ${ }^{32}$, se decide a publicar este artículo en la última etapa de su vida académica y personal. De nuevo aparece la visión de conjunto que caracteriza toda su obra: el contexto histórico de la emigración canario-americana, las zonas pobladas por las primeras familias salidas del archipiélago, el contingente humano (número de familias) que marchó a América... José Pérez Vidal extrapola

30 Vid. Pérez Vidal (1981).

31 Reproducido en Pérez Vidal (1991), por donde cito.

32 Indica que la encuesta mexicana hecha por Vicente T. Mendoza se llevó a cabo en septiembre 1940, pero sale a la luz por primera vez de la mano de Pérez Vidal en el Anuario de Estudios Atlánticos de 1984. 
la información dada por un único sujeto a las relaciones canario-mexicanas, pues, en última instancia, resulta una contribución destacable ${ }^{33}$ :

Tal vez resulte excesivo incluir el recuerdo de estas emigraciones masivas de canarios a América en el comentario de los materiales folklóricos isleños recogidos en Méjico. Sin embargo, esboza el amplio campo de influjos a que el pequeño haz folklórico canario-mejicano pertenece, y permite imaginar, en relación con estas muestras de la tradición poética, aportación de una sola mujer, la importancia de la contribución de tantas familias -además de los isleños sueltos- a la cultura tradicional de América en numerosos campos.

La colección folclórica recogida abarca cantos de cuna (arrorrós) $)^{34}$, $\operatorname{adivinanzas}^{35}$, folías ${ }^{36}$, romances $^{37}$ y un cuento ${ }^{38}$.

\section{RECENSIONES DE JOSÉ PÉREZ VIDAL}

Un apartado especial en la producción científica de José Pérez Vidal lo constituye el elevadísimo número de recensiones que el maestro palmero escribió a lo largo de toda su vida, buena parte de las cuales fue publicada en la Revista de Dialectología y Tradiciones Populares, otras en El Museo Canario (Las Palmas) y también en la Revista de Historia (La Laguna). Fueron estos unos años prolíficos para Pérez Vidal, período en el que su

33 Pérez Vidal hace notar que sobre la informante que ha suministrado los datos al profesor Mendoza, hubiese sido deseable saber algo más de ella, como por ejemplo en qué año llegó a México, la naturaleza de los demás miembros de su familia, el posible trato con otras familias canarias residentes en el país azteca, etc. Solo se sabe que en el año 1940 tenía cuarenta y cinco años y que procedía de Tenerife.

34 El más popular y conocido: "Duérmete, niño chiquito, / que tu madre no está aquí; / que fue a misa a San Antonio / y ella luego ha de venir".

35 Como por ejemplo: "Una señorita, / muy aseñorada, / nunca sale de casa / y siempre está mojada" [La lengua]. Idéntica versión en Cuba.

36 Popular es la siguiente: "Todas las Canarias son / hijas del Teide gigante: / mucha nieve en el semblante / y fuego en el corazón".

37 Muy difundido es el titulado "Alba Niña", que empieza: "Mañanita, mañanita, / mañana de la Ascención, / hallé mi casa enramada / con tres gajos de limón...".

38 "Se trata del tema de la niña perseguida que posee tres gracias maravillosas y es sustituida por la hija de la madrastra en su boda con el rey" (Pérez Vidal 1991: 185). 
maestría en el panorama humanístico español e internacional se iba haciendo cada vez más reclamada. Su labor, desde que entró a formar parte del Consejo Superior de Investigaciones Científicas (CSIC) de Madrid será fundamental para poder desarrollar y llevar a cabo publicaciones, proyectos, contactos con reconocidas personalidades, así como estar al día de las novedades que en el mercado editorial iban saliendo a la luz y que sin duda le dieron un profundo bagaje en varios campos a nuestro autor. Díaz Alayón (2005), al compilar el inventario bibliográfico de Pérez Vidal, resalta la importancia de pertenecer al CSIC:

En el año 1948 Pérez Vidal se incorpora al Consejo Superior de Investigaciones Científicas, al que estará ligado hasta el final de su vida profesional activa y en el que desarrollará una labor intensa, cada vez más reconocida. En un primer momento estará adscrito al Centro de Estudios de Etnografía Peninsular, que entonces dirigía Vicente García de Diego y que luego pasará a denominarse Departamento de Dialectología y Tradiciones Populares dentro del Instituto "Miguel de Cervantes". [... Todos estos años de estudio y dedicación quedan reflejados, de forma lógica, en la $R D T P$, que es el medio más cercano tanto por motivos profesionales como por intereses de índole científica y que nos proporciona abundantes referencias de una buena parte de la labor de Pérez Vidal en distintos niveles (Díaz Alayón 2005: 47).

La relación hecha por Díaz Alayón (2005) reúne hasta ahora la más amplia bibliografía de nuestro autor, con un total de 555 entradas, de las cuales $402(72.43 \%)$ pertenecen a las recensiones y $153(27.57 \%)$ a artículos en revistas, periódicos y gacetillas, libros y prólogos. En lo que se refiere a la vertiente americana de esta producción, es muy variada la nómina de autores y trabajos que reseñó, ya sea de artículos aparecidos en una heterogénea gama de revistas nacionales y extranjeras, ya sea en formato de libros que llegaban, muy posiblemente, con destino a los fondos de la biblioteca del CSIC y a los que el investigador palmero tenía fácil acceso. Por ello recoge innumerables referencias, informa de ellas, analiza y da a conocer los logros de trabajos procedentes de España, Portugal, Brasil, Uruguay, Venezuela, EE.UU., Colombia, México, República Dominicana, Argentina, Chile, Puerto Rico, Ecuador o Perú. Trabajos todos que formaban parte, de alguna manera, de la preocupación y curiosidad investigadoras de Pérez Vidal, a la vez que servían, como ya he indicado, de ampliación de sus conocimientos. Ocioso sería dar cuenta detallada de cada una de estas aportaciones, pero una mirada sucinta nos llevará al "mundo de Pérez Vidal" a través de lo que leyó y reseñó: sobre supersticiones y creencias populares, el folclore peninsular, canario y americano, la historia de las culturas precolombinas 
americanas, la huella lingüística de los canarios, el español de América y la filología en general, la cultura y poesía populares tanto en España, Portugal como en América, el tema tan importante para él del azúcar y sus ingenios, las creencias populares, el romancero hispánico, asuntos de etnología, antropología, la música, el cuento y sus cancioneros populares, la lengua portuguesa en Brasil, el arte tradicional, las palabras y cosas, la artesanía, el léxico específico de algún territorio americano, además de dar cuenta de más de una obra colectiva editada como homenaje ${ }^{39}$. Por supuesto, la nómina de autores ${ }^{40}$ es extensísima y puede decirse que muchas de las autoridades internacionales de cada especialidad fueron atendidas por la opinión de Pérez Vidal. Esta dedicación, desde mi punto de vista, supone también una importante producción en el terreno de la historiografía, pues el notorio número de recensiones traza también el quehacer investigador de una buena parte de las disciplinas humanísticas y es reflejo de las tendencias que estaban de moda en cada momento. A su vez, la labor de Pérez Vidal se erige en un pilar fundamental para difundir lo que en muchos sectores de la investigación se estaba haciendo en el "exterior", dada la precariedad de medios y alcances del ambiente científico español.

39 Tal es lo que ocurre con los Estudios de Filología e Historia literaria, homenaje al $R$. P. Félix Restrepo, publicado en Bogotá en 1949 o los dos volúmenes del Homenaje a Fritz Krüger editados por la Universidad Nacional de Cuyo (Mendoza-Argentina) en 1953 y 1954 respectivamente.

40 Como simple orientación se cuenta con los nombres de Raymond MacCurdy y su obra sobre el dialecto "canario" de la Louisiana, ya citado, de 1950; Rufino José Cuervo y sus Disquisiciones sobre Filología castellana (1950); Joseph Matluck, La pronunciación en el español del valle de México (1951); Luis Flórez, Lengua española (1953); Raúl Maldueño, Léxico de la borrachera... Palabras y coplas de América y España (1953); Federico E. Pais, Algunos rasgos estilísticos de la lengua popular catamarqueña (1957); Ángel Rosenblat, Lengua y cultura en Hispanoamérica (1948), Buenas y malas palabras en el castellano de Venezuela (1956), El castellano de España y el castellano de América. Unidad y diferenciación (1962); Manuel Álvarez Nazario, El arcaísmo vulgar en el español de Puerto Rico (1957); Raúl R. Maldueño, Ampliación y corrección de un léxico (1958); Avelino Herrero Mayor, Contribución al estudio del español americano (1965); Aura Gómez de Ivashevsky, Lenguaje colonial venezolano (1969); Peter Boyd-Bowman, Léxico hispanoamericano del siglo XV (1972); José Joaquín Montes Giraldo, Muestra del léxico de la poesía en Colombia (1973); Flérida de Nolasco, La poesía folklórica en Santo Domingo (s.a.); Miguel Ángel Acosta Saignes, Estudios de etnología antigua de Venezuela (1954); Vicente T. Mendoza, El corrido de la Revolución mexicana (1956); Serafim Sila Neto, Introduçao ao estudo da Lingua portuguesa no Brasil (1957); Luís da Cámara Cascudo, Rêde de dormir. Una pesquisa etnográfica (1959); Fritz Krüger, El mobiliario popular en los países románicos (1959) y El argentinismo "es de lindo" (1960); Susana Chertudi, Cuentos folklóricos de la Argentina (1960); Yolando Pino Saavedra, Cuentos folklóricos de Chile I (1960) y II (1961); Olga Fernández Latour, Cantares históricos de la tradición argentina (1961), y así hasta 402 títulos. 
Si se coteja esta considerable dedicación de Pérez Vidal al dar a conocer lo que se hacía en buena medida fuera de España, se observa el agudo análisis de sus opiniones y la generosidad con la que, en general, fue acogida la mayor parte de estas producciones. Puede decirse, al menos para la parte americanística que ahora nos interesa, que José Pérez Vidal reseñó con amplia visión intelectual y científica los distintos trabajos que cayeron en sus manos, especialmente aquellos que le eran más próximos por su interés investigador como etnógrafo. Merece la pena, ya sea sucintamente, que se destaquen algunos de sus comentarios, aparecidos en las decenas de páginas que redactó. Así, por ejemplo, sobre la obra de MacCurdy de 1950, referida al dialecto canario de la Louisiana (EE.UU.) señala que "Es, en resumen, un interesante estudio sobre la extraordinaria supervivencia de la lengua de una pequeña comunidad que se ha mantenido enquistada en medio de una cultura superior y absorbente"; sobre las Disquisiciones de Cuervo (1951) indica que es un acierto reunirlas ahora en un volumen, dado que muchas de las obras del insigne colombiano estaban diseminadas y eran de difícil acceso. Consciente también del estado en el que se encontraban los estudios del español americano, elogia positivamente las obras que dan a conocer esta realidad de la lengua en América. Así, considera que el trabajo de Matluck (1951) sobre el español del valle de México "es una valiosa aportación de materiales y observaciones para ese estudio de conjunto del español de América que ya se empieza a esbozar"; lo mismo sucede con los elogiosos comentarios hechos a los homenajes de Félix Restrepo (1949), autor del conocido El alma de las palabras, o Fritz Krüger (1953 y 1955), profesor que fue de la Universidad Nacional de Cuyo (Mendoza, Argentina); asimismo, destaca los valores que encuentra en las páginas del libro de Luis Flórez (1955), un volumen que recoge las intervenciones de su autor en la radio colombiana en programas de divulgación en los que se recomienda el buen uso del idioma. Aquí Pérez Vidal se detiene en el análisis de las voces relacionadas con el azúcar y Canarias, así como con la etimología de picúa, picuda y bicúa. En la misma línea de reseñar libros de divulgación general, aunque no carentes por ello de rigor científico, se encuentra el del ilustre Ángel Rosenblat (1956) con su conocido Buenas y malas palabras en el castellano de Venezuela, que compila artículos aparecidos en El Nacional de Caracas y que servirá, según su autor, de base al futuro diccionario de venezolanismos.

En este bosquejo que planteo de la dedicación de Pérez Vidal, me detengo brevemente en los comentarios que hizo en las recensiones de dos importantes trabajos. Uno es el de Avelino Herrero Mayor (1965) sobre el español americano. Pérez Vidal expone aquí con claridad cuál es su punto de vista sobre la realidad de nuestra lengua; posicionamiento que exige una 
altura de miras más allá de la visión estrictamente local y terruñera que en más de una ocasión se ha practicado y que ayuda a superar, como parece leerse entre líneas, las grandes controversias sobre la génesis de algún fenómeno a uno y otro lado del Atlántico. Reveladoras me han parecido, en este sentido, sus palabras que reproduzco en su totalidad:

He aquí un libro, un buen libro, en que se trata del español americano con un gran conocimiento no sólo de éste, sino también, como conviene, del español peninsular. Sólo así, en una visión general, se pueden formar juicios acertados de los distintos hechos y fenómenos lingüísticos que se manifiestan y producen en el español a un lado y otro del Atlántico. El enfoque total del español obliga, de una parte, a una gran altura científica y, de otra, a una actitud ecuánime ante todas las parcelas de la lengua. Por fortuna, estas cotas elevadas y desapasionadas en los estudios se alcanzan cada vez con más frecuencia, y como feliz resultado, las obras concebidas así, con espíritu abierto y dilatado, si todavía no menudean, ya no son tan raras $^{41}$.

Otro es la obra de Aura Gómez de Ivashevsky. A finales de la década de los años sesenta del siglo xx ya se estaban publicando numerosos trabajos que relacionaban los aspectos sociales y lingüísticos, y Pérez Vidal se hace eco de esta circunstancia en la reseña que hizo del libro de esta autora, que fue presentado, inicialmente, como Tesis doctoral en la Universidad de Madrid en 1965. Escribe ahora Pérez Vidal:

El título de esta obra ya declara perfectamente su contenido y la sitúa entre las que son resultado de una de las más modernas inquietudes de la Lingüística [...] Pero hoy, en esta nueva visión sincrónica, se tiende a estudiar el lenguaje en todas sus manifestaciones y se procura observar su vida en todos los niveles sociales. Consecuencia de esta preocupación por la lengua viva, son estudios sobre el habla coloquial, como el que ahora nos ocupa ${ }^{42}$.

En el terreno dedicado al folclore y, en general, a la etnografía, Pérez Vidal da cuenta de una variada gama de estudios y aportaciones. Si se rastrea su producción en esta parcela, se observa nítidamente cómo una de las constantes en su pensamiento y actitud es el hecho de que los trabajos merezcan el calificativo de "científicos" y que, por tanto, la etnografía

41 Recensión de Avelino Herrero Mayor, RDTP (1968), XXIV: 407-408.

42 Recensión de Aura Gómez de Ivashevsky, RDTP (1970), XXVI: 195. 
en su máxima extensión (con todo lo que ella abarca) tenga el rango de disciplina seria, rigurosa y científica, como la tienen otras ramas del saber humanístico. En este sentido, además, se pregunta sobre cuál es el lugar que ocupa en el mundo de la Universidad esta disciplina: “¿De qué modo habrá que lamentarse en aquellos países en que la etnografía y el folklore no han entrado en ninguna Universidad si no es a modo de complemento pintoresco de algún curso para extranjeros?" ${ }^{43}$. Por ello, en numerosas recensiones hace hincapié en la aportación científica ${ }^{44}$ del estudio o, si es el caso, en la falta de la misma ${ }^{45}$.

Pérez Vidal ejemplificó, como vemos, la actitud del humanista moderno que condensa en su persona varias ramas del saber; que fue consciente de que las disciplinas, lejos de ser compartimentos estancos, separados e infranqueables, son, por el contrario, vasos comunicantes que permiten la comprensión y explicación de numerosos hechos. Por todo ello, recalca una y otra vez que muchos de los materiales de los que dispone el etnógrafo, también son de utilidad para el dialectólogo, y viceversa. $\mathrm{Y}$ así se advierte en varias recensiones dedicadas a los temas etnográfico-dialectales. En este camino se encuentran los comentarios de la compilación hecha por B. A. Gutiérrez (1950) sobre los elementos tradicionales del Estado de Antioquia (Colombia); Nieves de Hoyos Sancho (1950) y la quema del Judas, que relaciona con Canarias (La Palma), o Flérida García de Nolasco y la poesía folclórica de Santo Domingo (1953), importante al ser La Española el portal de América, entre otras muchas.

La misma concepción que se ha visto para el terreno puramente lingüístico se aplica también para el etnógrafo y folclorista, ya que estos no deben cerrarse en su mundo local o regional. Así lo deja ver al dar cuenta de la publicación de la obra de Flérida García de Nolasco ${ }^{46}$; lo mismo destaca de la obra del etnógrafo venezolano Miguel Acosta Saignes, de quien dice que

43 Recensión de Ralph Steele Boggs, RDTP (1956), XV: 187.

44 José Pérez Vidal: “de muy subido interés”, en la recensión de Raúl R. Madueño, RDTP (1959), XV; "solvencia científica de los materiales", en la recensión de Susana Chertudi, RDTP (1960), XVI; "gran criterio científico", en la recensión de Olga Fernández Latour, RDTP (1961), XVII; "es el presente, como se ve, un libro perfecto, hecho con un gran sentido de la responsabilidad científica", en la reseña de Fritz Krüger, RDTP (1964), XX; "ha logrado indiscutibles aportaciones científicas", en la reseña de Rodolfo M. Casamiquela, RDTP (1967), XXIII (1967), y así muchos ejemplos más.

45 José Pérez Vidal: Recensión de B[uenaventura] Caviglia (hijo), RDTP (1949), v: $517-$ 518. De las reseñas consultadas por mí, resulta ser esta la más crítica de Pérez Vidal y en la que resalta la falta de criterios científicos empleados por el autor.

46 Recensión de Flérida García de Nolasco, RDTP (1956), XII: 547-548. 
está lejos de todo patriotismo y localismo ${ }^{47}$. En la recensión que publica de la obra de Paulo de Carvalho Neto ${ }^{48}$ resalta que "Estos resultados han hecho concebir la investigación etnográfica como un ejercicio de convivencia y han dado a los etnógrafos un puesto excepcional en el movimiento de aproximación y comprensión mutua de los pueblos". Sostiene, al igual que otros etnógrafos, que frente a la disparidad etnográfica, se haya hablado, por un autor italiano, de la fratellanza de las tradiciones populares ${ }^{49}$. Para él, es más lo que existe de común que lo que las singulariza y reduce.

\section{PÉREZ VIDAL Y SU CORRESPONDENCIA SOBRE AMÉRICA}

La correspondencia que a lo largo de su vida José Pérez Vidal mantuvo con numerosas personas e instituciones acerca de su labor como investigador es interesante y muestra, además, las dificultades propias de cada época en las que la lejanía, el tiempo, las disponibilidades materiales y económicas condicionaban el rumbo de cada investigación. Las fuentes que me han sido proporcionadas $^{50}$ no contienen referencias explícitas a temas americanos, salvo las que se refieren a asuntos generales o aquellos que tienen que ver, básicamente, con el campo de los ingenios de azúcar.

En este último terreno, por solo citar unos ejemplos, Pérez Vidal tuvo una intensa correspondencia en la que requería información sobre el cultivo de los ingenios de azúcar, como se ve en la carta que recibe de D. A. Gómez Felipe [18 de julio de 1952], en la que trata de temas históricos de la caña de azúcar y el trapiche y en la que se incluye, además, un esquema del mismo. De igual forma, las necesidades económicas para sufragar una investigación quedan reflejadas en la correspondencia que Pérez Vidal mantiene con el Presidente del Patronato Menéndez Pelayo del CSIC. El 22 de octubre de 1952 solicita una ayuda económica de 2.500 pesetas para la realización de un viaje a Málaga, Granada y Almería para estudiar in situ el cultivo de la caña

47 Recensión de Miguel Acosta Saignes, RDTP (1956), XII: 548-549.

48 Recensión de Paulo de Carvalho Neto, RDTP (1962), XVIII: 548.

49 Se refiere a Angelo Dalmedico y su obra Della fratellanza dei popoli nelle tradizioni comuni.

50 Procedentes todas del Archivo-Biblioteca José Pérez Vidal de Santa Cruz de La Palma (La Palma. Islas Canarias). 
de azúcar ${ }^{51}$. En la misma línea está la petición que hizo a los gobernadores de Málaga, Granada y al Presidente de la Diputación Provincial de Málaga ${ }^{52}$, instituciones de las que recibe una negativa en cuanto a la ayuda económica por no existir presupuesto.

Pérez Vidal se carteó con una variada gama de personas para recabar información sobre la recogida, las técnicas y los materiales bibliográficos relacionados con el azúcar. Y así solicitó a Orlando Ribeiro (de la Universidad de Lisboa) información sobre los ingenios de azúcar en Madeira [28 de abril de 1953]; Laureano Baco [30 de abril de 1953] -que es respuesta a una misiva de Pérez Vidal del 24 de abril de ese mismo año- le aporta información del libro de Francisco Bueno García, quien había escrito sobre el azúcar y la miel. Igualmente sobre los ingenios del mediodía peninsular, particularmente de la zona de Málaga, mantiene una fluida correspondencia. Sirvan de ejemplos las siguientes que se citan: carta a Antonio Son Cerezo (Nerja. Málaga) en la que solicita la venta de fotografías sobre las faenas de la caña de azúcar [10 de junio de 1953]. Carta a Andrés Félez de la Azucarera Hispania (Málaga) en la que le pide fotografías del cultivo y recolección de la caña de azúcar. Ruega precisión en el detalle y que también está dispuesto a pagar por las fotos, además de citar su procedencia [16 de junio de 1953]. También ese mismo día, redacta otra carta dirigida al Gerente del Ingenio Ntra. Sra. del Carmen Frigiliana en la que agradece la acogida en la fábrica de su encargo y solicita fotos de la rueda hidráulica y cualquier otra cosa de interés. Carta del Director Gerente de "La Torre" (Nerja. Málaga) en la que le envía nueve fotografías de la fábrica, del cultivo y de la recolección del azúcar. Se detalla información sobre la miel de caña ${ }^{53}$. En el caso de Portugal, Pérez Vidal escribe, según los fondos que he consultado, el 29 de junio de 1953 una carta al Presidente de la Cámara Municipal de Funchal en la que le pide información sobre los "engenhos" de la caña y pide microfilm de Gaspar Frutuoso del tomo dedicado a la isla ${ }^{54}$. Lo mismo hace con la petición dirigida al Director de la Biblioteca Comunale de Palermo (Sicilia.

51 El 16 de febrero de 1953, Pérez Vidal, al no haber recibido contestación de dicha solicitud, retira su petición de ayuda. Sin embargo, el 11 de marzo de 1953, el Vicesecretario del CSIC le confirma la concesión de la ayuda solicitada el 22 de octubre de 1952.

52 Solicita información sobre las vegas azucareras y la posibilidad de ayuda económica. Carta del 27 de mayo de 1953.

53 Contesta Pérez Vidal el 10 de julio de 1953 agradeciéndole el envío y asimismo solicita información y datos sobre el nombre popular del sistema de plantación en terreno escalonado.

54 El 24 de julio de 1953 João Gonçalves Valente, Presidente de la Cámara Municipal de Funchal, le contesta dándole la información requerida casi un mes antes. 
Italia) en la que encarga microfilm de los manuscritos de aprovechamiento de la caña de azúcar en la isla [2 de septiembre de 1953], o con el Director del Instituto del Azúcar y el Alcohol de Río de Janeiro (Brasil) a quien le pide el envío de un ejemplar de la obra Historia do Açucar de Edmundo von Lipmann, con traducción de Rodolfo Cotinho, además de otras obras ${ }^{55}$ [12 de septiembre de 1953]. Del 2 de febrero del año 1961 es el comunicado que recibe Pérez Vidal de la Secretaría del Instituto de Alta Cultura de Lisboa en el que se le informa de la concesión de una ayuda económica para auxilio de su viaje a Portugal, con el objetivo de visitar los archivos de Coimbra, con destino a su trabajo sobre la influencia de la cultura portuguesa en las Islas Canarias. Por último, el 29 de diciembre de 1969, Pérez Vidal contacta con Vicente Vidal Corella para rogarle que le dé más datos de un artículo titulado "El turrón y los Reyes Católicos" y cualquier apunte bibliográfico sobre el azúcar en la zona de Valencia.

\section{FINAL}

La amplia formación académica del ilustre profesor palmero se deja traslucir en su importante contribución a las relaciones canario-americanas. Toda su obra, como ya se ha indicado supra, está plagada de referencias, trabajos específicos y de ecos de los vínculos históricos (y en definitiva humanos) de lo que de canario hay en América y de lo que de americano hay en las Canarias. Como investigador y apasionado de ese amplísimo mundo compartido - en una generosa visión de conjunto-, José Pérez Vidal sentó las bases de una segura comparación e indagación no solo a lo largo de toda su fructífera vida académica y profesional, sino también de lo que posteriormente se ha continuado.

Cumplido ya el primer centenario de su nacimiento en el año 2007, estas páginas quieren recordar y estudiar su obra en el contexto de la historiografía actual, sus grandes aciertos y la huella, siempre constante, de quien ha

55 El 4 de marzo 1954, Pérez Vidal escribe al Embajador de Brasil para rogarle que le done un ejemplar de la obra de Lipmann, puesto que en otros sitios está agotada y no tiene posibilidad de conseguirla. En situación similar se había encontrado meses antes, cuando recibe una carta de Rafael García Granados en la que le comunica a Pérez Vidal que el libro solicitado, La industrialización del azúcar en Nueva España, no está a la venta, pero que puede conseguirle un ejemplar. 
ocupado un primerísimo puesto en el terreno científico internacional y de quien puede considerarse, en esta misma dimensión, un canario universal.

\section{REFERENCIAS BIBLIOGRÁFICAS}

Alvar, M. 1969. Adaptación, adopción y creación en el español de las Islas Canarias. En su Variedad y unidad del español: estudios lingüísticos desde la historia, pp. 147-174. Madrid: Editorial Prensa Española.

1990. El camino de las Indias: significación de las Islas Canarias. En su Norma lingüistica sevillana y español de América, pp. 63-84. Madrid: Ediciones Cultura Hispánica.

Cabrera Déniz, G. J. 1991. Prensa canaria en América. En F. Morales Padrón (coord.). VIII Coloquio de Historia Canario-Americana (1988), pp. 317-333, vol. II. Las Palmas de Gran Canaria: Cabildo Insular de Gran Canaria.

Catalán, D. 1974. Lingüística íbero-románica. Crítica retrospectiva. Madrid: Gredos.

Corrales, C. y D. Corbella. 2001. Diccionario histórico del español de Canarias. La Laguna: Instituto de Estudios Canarios.

2010. Tesoro léxico canario-americano. Cabildo de Gran Canaria-Casa de Colón: Gran Canaria.

Cuervo, R. J. 1901. El castellano en América. Bulletin Hispanique III: 35-62.

Díaz Alayón, C. 1991. Las relaciones lingüísticas entre Canarias y América. En F. Morales Padrón (coord.). VIII Coloquio de Historia Canario-Americana (1988), pp. 709-728, vol. II. Las Palmas de Gran Canaria: Cabildo Insular de Gran Canaria.

(ed.). 1993. Homenaje a José Pérez Vidal. La Laguna: Cabildo Insular de La Palma et al.

2005. Inventario bibliográfico de José Pérez Vidal. Revista de Estudios Generales de la isla de La Palma 1: 45-89.

Fernández, D. W. 1956-57. Los periódicos canarios en América. El Museo Canario 57-64: 157-163.

Fortier, A. 1894. The isleño of Louisiana and Their Dialect. Louisiana Studies. Litterature, Customs and Dialects. History and Education, pp. 197-210. Nueva Orleans.

Henríquez Ureña, P. 1930. Observaciones sobre el español en América. II. Revista de Filología Española XVIII: 277-284.

Hernández García, J. 1981. La emigración de las islas Canarias en el siglo XIX. Las Palmas de Gran Canaria: Cabildo Insular de Gran Canaria.

López, E. y A. Cea. 1987. José Pérez Vidal: entrevistas sobre su vida. Santa Cruz de La Palma: Cabildo Insular de La Palma.

2007. José Pérez Vidal: una larga entrevista. Santa Cruz de La Palma: Cabildo Insular de La Palma. 
MacCurdy, R. 1950. The Spanish Dialect in St. Bernard Parish. Alburquerque: Universidad de Nuevo México.

Medina LóPez, J. 1999. El español de Canarias en su dimensión atlántica: aspectos históricos y lingüisticos. Valencia: Tirant lo Blanch y Universitat de València.

2008. Cincuenta años de investigación lingüística canario-americana (19552005). En C. Hernández Alonso y L. Castañeda San Cirilo (eds.). El español de América. Actas VI Congreso Internacional de "El Español de América", pp. 771-787. Valladolid: Diputación de Valladolid.

Morales Padrón, F. 1956. Canarias en América y América en Canarias. Revista de Estudios Americanos 62/XII: 355-366.

Pérez Bustamante, C. (1941): Las regiones españolas y la población de América (1509-1534). Revista de Indias II: 81-120.

Pérez Vidal, J. 1933. Díaz Pimienta y la construcción naval española en el siglo XVII: nuevos documentos, nuevas noticias. Las Palmas de Gran Canaria: Tip. Editorial Canaria. [Rec.: El Museo Canario 2 (1934): 103-105]. [Reimp.: Pérez Vidal 1982: 53-106].

1934. Díaz Pimienta, señor de Puerto Real. El Museo Canario 4: 37-47. [Reimp. Pérez Vidal 1982: 107-119].

1943. El poema más antiguo de la poesía cubana. Revista de Historia IX/61: 68-70.

1944. Influencias geográficas en la poesía tradicional canaria. Madrid: Publicaciones de la Real Sociedad Geográfica, serie B, núm. 158.

1945. Don Valeriano Fernández Ferraz en la Universidad de La Habana (18831890). El Museo Canario 14: 69-89.

1955. Aportación de Canarias a la población de América: su influencia en la

lengua y en la poesía tradicional. Anuario de Estudios Atlánticos 1: 91-197. [Reimp.: Pérez Vidal 1991: 7-134].

1959. España en la historia del tabaco. Madrid: CSIC.

1960. Las Canarias, vía de introducción de portuguesismos en América. En

Actas do Colóquio de Estudos Etnográficos "Dr. José Leite de Vasconcelos", pp. 359367, v. III. Oporto.

1970. Contribución luso-española a la cultura y al léxico azucareros latinoamericanos. En Colóquio do XXIX Congresso Luso-Espanhol para o Progresso das Ciencias, pp. 1-12, t. III. Lisboa: Public. de la Associação portuguesa para o progresso das Ciencias.

1973. La cultura de la caña de azúcar en el Levante español. Madrid: CSIC.

1976. Díaz Pimienta y la construcción naval en el astillero de Guarnido. En XL Aniversario del Centro de Estudios Montañeses, pp. 361-366. Santander: Diputación Provincial de Santander.

1981. Canarias, el azúcar, los dulces y las conservas. En II Jornadas de Estudios Canarias-América, pp. 173-193. Santa Cruz de Tenerife: Caja General de Ahorros.

1982. El Almirante Díaz Pimienta: nuevos documentos, nuevas noticias. Santa Cruz de La Palma: Cabildo Insular de La Palma.

1984. Poesía tradicional canaria en Méjico. Anuario de Estudios Atlánticos 30:

111-154. [Reimp.: Pérez Vidal 1991: 135-185].

1986. V. Fernández Ferraz: un krausista español en América. Las Palmas de Gran Canaria: Cabildo Insular de Gran Canaria.

1988. Juan Fernández Ferraz, periodista y educador en Costa Rica. En Serta gratvlatoria in honorem Juan Régulo, pp. 725-745, v. III. La Laguna: Universidad de La Laguna. 
1991. Aportación de Canarias a la población de América: su influencia en la lengua y en la poesía tradicional. Las Palmas de Gran Canaria: Ediciones del Cabildo Insular de Gran Canaria.

Rodríguez ArzúA, J. (1947): Las regiones españolas y la población de América. 1509-38. Revista de Indias VIII: 695-748.

Samper Padilla, J. A. 1994. Relaciones lingüísticas entre Canarias y América: estado de la cuestión. En F. Morales Padrón (coord.). X Coloquio de Historia Canario-Americana (1992): 1174-1198, v. I. Las Palmas de Gran Canaria: Cabildo Insular de Gran Canaria.

Trapero, M. 1993. La obra de Pérez Vidal y sus estudios sobre el romancero. En C. Díaz Alayón (ed.). Homenaje a José Pérez Vidal, pp. 59-74. Cabildo Insular de La Palma et al., La Laguna. 